\title{
Detection of lard in vegetable oils.
}

\begin{abstract}
The presence of animal fats, in particular lard (pig fat), in any product is of real concern to some communities, especially Muslims and Jews, due to the religious prohibition of these commodities. This is especially so when lard is used as substitute for vegetable oils in foods or other consumer goods such as cosmetics and pharmaceuticals. Manufactures and producers alike should be sensitive towards the issues of unlawful material in these products as halal and kosher markets are expected to proliferate in the coming years. This article highlights some analytical techniques proposed to detect and to quantify lard in vegetable oils such as Fourier transform infrared (FTIR) spectroscopy, differential scanning calorimetry (DSC), chromatographic-based techniques, and electronic nose (EN).
\end{abstract}

Keyword: Nalytical techniques; Animal fat; Consumer Goods; Electronic nose. 